\title{
Susceptibility to liver fibrosis in mice expressing a connective tissue growth factor transgene in hepatocytes
}

\author{
ZhenYue Tong ${ }^{1,{ }^{*}, \text { Ruju Chen }}{ }^{1,{ }^{*}, \text { Daniel S Alt }}{ }^{1}$, Sherri Kemper ${ }^{1}$, Bernard Perbal ${ }^{2}$, and David \\ R Brigstock ${ }^{1,3}$ \\ ${ }^{1}$ Center for Cell and Developmental Biology, The Research Institute at Nationwide Children's \\ Hospital, Columbus Ohio 43205 USA \\ ${ }^{2}$ Laboratoire d'Oncologie, Virale et Moléculaire, UFR de Biochimie, Université Paris 7-D. Diderot, \\ 2 Place Jussieu 75 005, Paris, France \\ ${ }^{3}$ Departments of Surgery and Molecular and Cellular Biochemistry, The Ohio State University, \\ Columbus $\mathrm{OH} 43205$ USA
}

\begin{abstract}
Connective tissue growth factor $(\mathrm{CCN} 2)$ is a matricellular protein that is up-regulated in many fibrotic disorders and co-expressed with transforming growth factor beta. CCN2 promotes fibrogenesis and survival in activated hepatic stellate cells, and injured or fibrotic liver contains up-regulated levels of $\mathrm{CCN} 2$ which are produced by a variety of different cell types, including hepatocytes. To investigate CCN2 action in vivo, transgenic FVB mice were created in which the human CCN2 gene was placed under the control of the albumin enhancer promoter to elevate hepatocyte CCN2 levels. Production of hCCN2 mRNA and elevated CCN2 protein levels was demonstrated in transgenic livers, while levels of endogenous mouse CCN2 were comparable between transgenic and wild-type mice. Liver histology and liver function tests were unaffected in transgenic animals. However, after chronic administration of carbon tetrachloride $\left(\mathrm{CCl}_{4}\right)$, alphasmooth muscle actin ( $\alpha$-SMA)-expressing cells and collagen deposition were increased as a function of the dosage of the hCCN2 transgene (i.e. $h c c n 2+/+>h c c n 2+/->h c c n 2-/-)$. Moreover, $\mathrm{CCl}_{4}$-induced serum hyaluronic acid, hepatic tissue levels of $\alpha$-SMA or acid-soluble collagen, and mRNA expression of $\alpha$-SMA, collagen $\alpha 1$ (I), matrix metalloprotease- 2 , or tissue inhibitor of metalloprotease- 1 were greater in transgenic mice than in wild-type mice. Transgenic mice also exhibited enhanced hepatic deposition of collagen two weeks after bile duct ligation Conclusion: Production of elevated CCN2 levels in hepatocytes of transgenic mice in vivo does not cause hepatic injury or fibrosis per se but renders the livers more susceptible to the injurious actions of other fibrotic stimuli. These studies support for a central role of CCN2 in hepatic fibrosis and demonstrate a role of the micro-environment in regulating the pro-fibrotic action of CCN2.
\end{abstract}

\section{Keywords}

matricellular; CCN2; CTGF; fibrogenesis; hepatic stellate cell

Connective tissue growth factor (CCN2) is 349-residue mosaic protein that participates in critical processes such as differentiation, development, tumor growth, angiogenesis, placentation, and wound healing (1). The actions of CCN2 are complex and reflect its

Correspondence to: David R. Brigstock, Ph.D, Center for Cell and Developmental Biology, Room WA2022, The Research Institute, Nationwide Children's Hospital, 700 Children's Drive, Columbus OH 43205, Tel 614-355-2824; Fax 614-722-5892;

David.Brigstock@NationwideChildrens.Org.

Z Tong and R Chen contributed equally to this work 
function as a matricellular protein whereby it resides as a non-structural matrix- or cellassociated molecule that regulates cellular responsiveness to a myriad of extracellular signals and environmental cues (2). These actions are likely achieved, at least partly, through its engagement of specific integrins and heparan sulfate proteoglycans on the cell surface (2).

Fibrosis is the most common pathophysiological condition in which $\mathrm{CCN} 2$ has been implicated and fibrotic conditions in the liver, lung, kidney, heart and skin are all strongly associated with CCN2 overexpression (1). In the liver, CCN2 mRNA expression is elevated in patients suffering from chronic viral hepatitis, primary biliary cirrhosis, primary sclerosing cholangitis, cryptogenic, alcoholic liver disease, congenital hepatic fibrosis or non-alcoholic steatohepatitis (3). CCN2 expression is also elevated in fibrotic livers from rodents subjected to bile duct ligation or exposure to carbon tetrachloride $\left(\mathrm{CCl}_{4}\right)$ or $\mathrm{N}$ nitrosodimethylamine (4-6). High hepatic levels of CCN2 are associated with its entry into the circulation, as demonstrated by higher serum CCN2 concentrations in patients with biliary atresia or chronic viral hepatitis compared to control patients, with increasing CCN2 concentrations correlating with the progression of liver fibrosis $(7,8)$

Hepatocyte-derived CCN2 likely contributes to fibrotic pathways in the liver, at least in part, via its paracrine stimulation of activated $\mathrm{HSC}$ in which fibrogenic and survival pathways are promoted by CCN2 $(3,9)$. Hepatocyte expression of CCN2 is usually low but it is enhanced in response to liver injury or insult such as partial hepatectomy, drug-induced toxicity, ethanol metabolism, infection with hepatitis $C$ virus, or cancer (10-13). This effect may be due in part to the inductive action of TGF- $\beta$ which stimulates CCN2 expression in hepatocytes via activation of PiI3K/p38MAPK and/or ALK5-dependent Smad 3 (14,15). In these studies, we have investigated the pro-fibrotic aspects of elevated hepatocyte CCN2 levels in transgenic mice in which the human $\mathrm{CCN} 2$ gene was expressed under the control of the albumin enhancer promoter.

\section{Materials and Methods}

\section{Cloning of human CCN2 expression vector}

A 6600bp SacI fragment of human CCN2 (hCCN2) genomic DNA (16) was amplified by PCR using forward primer 5'-CGTGCCAACCATGACCGA-3' and reverse primer 5'CGGAATTCTCTAATGAGTTAATGTCTCTCACTCTCTG-3'. The resulting product was digested with SacII and EcoRI and ligated into the SacII / EcoR1 sites of pTRE (Clontech, Mountain View CA) to produce "pTRE/hCCN2". To achieve expression by hepatocytes, the CMV promoter in pTRE/hCCN2 was replaced with the mouse albumin enhancer/promoter sequence in pBluescript (KS-) plasmid p2335A-1 (17). Briefly, a 2.3-kb SacI / Kpn fragment from $\mathrm{p} 2335 \mathrm{~A}-1$ containing the mouse albumin enhancer/promoter was blunted by T4 DNA polymerase and ligated into the blunted Xhol/SacII sites of pTRE/hCCN2 to generate "pALB/hCCN2" (Figure 1A) which was confirmed by nucleotide sequencing.

\section{pALB/CCN2-mediated CCN2 over-expression in hepatocytes in vitro}

FL83B mouse hepatocytes (American Type Culture Collection, Manassas, VA) were grown in 6-well plates in Hams F-12 medium (Mediatech Inc, Manssas VA) containing 10\% bovine serum. At $\sim 80 \%$ confluency, the medium was replaced with $1 \mathrm{ml}$ fresh Hams F-12 medium containing $2 \%$ bovine serum and $15 \mu \mathrm{l} \mathrm{FuGene} 6$ transfection reagent (Roche Diagnostics Corp. Indianapolis, IN). Cells were then transfected with $2 \mu \mathrm{g}$ pALB/hCCN2 for 48 hours. RNA was isolated using RNA STAT-60 Total RNA Isolation Reagent (Tel Test Inc., Friendswood, TX). Reverse transcriptase polymerase chain reaction (RT-PCR) was performed on $2 \mu \mathrm{g}$ total RNA using SuperScript II Reverse Transcriptase (Invitrogen) to 
generate the cDNA. The conditions for the reverse transcriptase reaction were: $25^{\circ} \mathrm{C}$ for $10 \mathrm{~min}, 42^{\circ} \mathrm{C}$ for $50 \mathrm{~min}$ and $70^{\circ} \mathrm{C}$ for $15 \mathrm{~min}$ followed by PCR using the following primers : hCCN2 (632bp): 5'-TCCCTGCATCTTCGGTGGTA-3' and 5'CCTCGCCGTCAGGGCAC-3'; mouse CCN2 (mCCN2) (734bp): 5'CCGCACTGCCCCGCC-3' and 5'-CCCGCAGAACTTAGCCC-3'; and $\beta$-actin (324bp): 5'AGCTTGCTGTATTCCCCTCCATCGTG-3' and 5'AATTCGGATGGCTACGTACATGGCTG-3'. PCR conditions were 2 mins at $94^{\circ} \mathrm{C}, 35$ cycles at $94^{\circ} \mathrm{C}$ for $30 \mathrm{sec}$, annealing at $56^{\circ} \mathrm{C}$ for $40 \mathrm{sec}$, and $72^{\circ} \mathrm{C}$ for $1.5 \mathrm{~min}$, followed by final extension for $10 \mathrm{mins}$ at $72^{\circ} \mathrm{C}$. For the last 6 hours of the 48 -hour transfection period, the cells were metabolically labeled with $100 \mu \mathrm{Ci} / \mathrm{ml}\left[{ }^{35} \mathrm{~S}\right]$ cysteine/methionine (Trans ${ }^{35} \mathrm{~S}$ label, MP Biomedical, Irvine, CA) prior to lysis in immunoprecipitation buffer $(50 \mathrm{mM}$ TrisHCl (pH7.4) containing 150mM NaCl, $1 \%$ NP- $40,0.25 \%$ DOC, $1 \mathrm{mM}$ EDTA, and $0.1 \%$ SDS) and subsequent pull-down of $100 \mu \mathrm{g}$ total cellular protein with anti-CCN2 (18) or Western blot of $50 \mu \mathrm{g}$ protein using monoclonal anti- $\beta$-actin (clone AC-15; Sigma-Aldrich, St. Louis, MO).

\section{Generation of $\mathrm{pALB} / \mathrm{CCN} 2$ transgenic mice}

Animal procedures were approved by the Institutional Animal Care and Use Committee of The Research Institute at Nationwide Children's Hospital (Columbus, OH).

A 7.1kb linearized fragment of Not1-digested pALB/hCCN2 (Fig.1A) was microinjected into single-cell $\mathrm{FVB} / \mathrm{n}$ mouse eggs which were then implanted into pseudo-pregnant female $\mathrm{FVB} / \mathrm{n}$ mice (The Jackson Laboratory, Bar Harbor, ME), yielding 30 offspring (3 litters) of which two ( 1 male, 1 female) were positive for ALB/hCCN2 DNA by PCR screening (data not shown). Using these as founders, two essentially identical transgenic lines ("ZY1", "ZY2") were established. Data reported here were obtained from the ZY2 line which has been maintained continuously for 60 months. All of the experiments described were performed on male mice between 4 and 28 weeks of age. The three genotypes ( $h c c n 2+/+$, hccn2+/-, hccn2-/-) required for this study were initially determined by screening using semi-quantitative PCR and Southern blot, and then confirmed by quantitative real-time PCR (Q-RTPCR).

\section{Carbon tetrachloride administration}

Wild-type or transgenic male mice that were 4-6 weeks of age were injected i.m. once per day on 4 successive days each week for 5 weeks with either $30 \mu \mathrm{l}$ of vegetable oil or a mixture of $0.5 \mu \mathrm{CCl}_{4}$ (Sigma-Aldrich) in $29.5 \mu \mathrm{l}$ of vegetable oil. This dose of $\mathrm{CCl}_{4}$ induced sub-maximal hepatic fibrosis in wild-type FVB mice as established from doseresponse studies (data not shown). Upon sacrifice, blood was collected and individual liver lobes were tied and harvested either immediately and snap-frozen in liquid nitrogen for subsequent RNA or protein extraction, or after in situ perfusion using PBS followed by $4 \%$ paraformaldehyde (Sigma-Aldrich) for histological analysis of fixed tissue.

\section{Ethanol administration}

Wild-type FVB mice received ethanol $(6 \mathrm{~g} / \mathrm{kg})$ or saline i.p. at 0,8 and 16 hours prior to sacrifice at 24 hours. A portion of the liver was fixed and processed for in situ hybridization (ISH) to detect mCCN2 mRNA, while hepatocytes were isolated from the remainder of the fresh unfixed liver tissue by in situ collagenase digestion (19) and subjected to fluorescence activated cell sorting (FACS) using anti-CCN2 antibody essentially as described (20). 


\section{Bile duct ligation (BDL)}

BDL or sham operations were performed on 4-6 week $h C C N 2-/-$ or $h C C N 2+/+$ mice as described (21), after which the animals were maintained under normal housing conditions for 14 days. During this period, survival was $>90 \%$ in all groups of mice. On Day 14 postsurgery, mice were sacrificed and their livers were processed for histological evaluation.

\section{Semi-quantitative PCR}

Three-week old mice were genotyped by PCR of DNA obtained from tail clippings. DNA was isolated by sequential protease K digestion and phenol-chloroform extraction. PCR was performed using transgene-specific primers, one of which apnned the junction between the albumin enhancer/promoter and hCCN2 (Figure 1A; P1: 5'-

AGAGCGAGTCTTTCTGCACACA-3'; P2: 5'-GAGAGAATCACGACCCTGACTT-3'). PCR conditions were $2 \mathrm{~min}$ at $94^{\circ} \mathrm{C}, 35$ cycles at $94^{\circ} \mathrm{C}$ for $30 \mathrm{sec}$, annealing at $55^{\circ} \mathrm{C}$ for 40 sec, and extension at $72^{\circ} \mathrm{C}$ for $1.5 \mathrm{mins}$, followed by $10 \mathrm{mins}$ at $72^{\circ} \mathrm{C}$. The $1044 \mathrm{bp} \mathrm{hCCN} 2$ PCR product was detected by ethidium bromide staining after agarose gel electrophoresis.

Southern Blot-Genomic DNA (5 $\mu \mathrm{g}$ ) from mice tails was digested in a $40 \mu \mathrm{l}$ final volume with 20U Stu I in Reaction buffer II (New England Biolabs, Ipswich, MA). DNA fragments were separated in a $0.7 \%$ agarose gel and transferred to Hybond $\mathrm{N}+$ membrane (Amersham-Pharmacia, Piscataway, NJ). The membrane was probed with a previously described $1.1 \mathrm{~kb}$ human CCN2 cDNA (18) that was labeled using Radprime labeling kit (Invitrogen).

\section{Quantitative PCR (Q-PCR)}

Q-PCR was performed with TaqMan-minor groove binder, primers, probes and TaqMan Universal Master Mix using an ABI Prism 7500 machine (all from Applied Biosystems Inc, Foster City, CA). Primers were designed using Primer Express Software (version 3.0; Applied Biosystems,). Genotypes were established by determination of the amount of hCCN2 product relative to that of mouse glucagon after 40 cycles. Specific conditions were $50^{\circ} \mathrm{C}$ for $2 \mathrm{~min}, 95^{\circ} \mathrm{C}$ for $10 \mathrm{~min}, 40$ cycles of $95^{\circ} \mathrm{C}$ for $15 \mathrm{secs}$, and then $58^{\circ} \mathrm{C}$ for $1 \mathrm{~min}$. Each amplification reaction was performed in triplicate on $20 \mathrm{ng}$ of genomic DNA. The number of transgene copies was established from hCCN2 plasmid DNA standard curves. Sequences were: hCCN2 forward primer: CATCCCCCACCCCTCTCT; hCCN2 reverse primer: CCGTACCACCGAAGATGCA; hCCN2 probe: TCTCCAGCCAAAGAT; glucagon forward primer: CACAACATCTCGTGCCAGTCA; glucagon reverse primer: ATCTGCATGCAAAGCAATATAGCT; and glucagon probe: TGGGATGTACAATTTCAA.

\section{Histology}

Perfused livers were fixed with $4 \%$ paraformaldehyde for 24 hours and then embedded in paraffin. Sections of $5 \mu \mathrm{m}$ thickness were cut and stained with hematoxylin and eosin $(\mathrm{H}$ and E). For immunohistochemical detection of alpha-smooth muscle actin ( $\alpha$-SMA), slides were incubated with monoclonal mouse anti- $\alpha$-SMA IgG (Dako, Glostrup, Denmark) followed by development with UltraTek reagents and AEC chromogenic substrates (all from ScyTek Laboratories, Logan, UT) and hemotoxylin counterstain. CCN2 immunohistochemistry was performed using affinity-purified rabbit anti-CCN2 IgG as described (22). CCN2 in situ hybridization was performed with digoxygenin-labelled RNA sense or antisense probes generated from a pCRII vector containing mCCN2 cDNA (23). Collagen was detected by staining sections with $0.1 \%$ Sirius Red (Sigma-Aldrich). Protein staining for $\alpha$-SMA or collagen was quantified over ten $20 \times$ fields per mouse using ImagePro ${ }^{\mathrm{TM}}$ software (Media Cybernetics Inc, Bethesda, MD). 


\section{RT-PCR and Q-RTPCR of liver RNA}

RT-PCR of CCN2 mRNA isolated from frozen liver tissue was performed as described above for FL83B mouse hepatocytes. For Q-RTPCR of mouse liver RNA, the reversetranscription step was performed as described above for mouse FL83B cells. Real-time amplification was then performed with SYBR®Green PCR Master Mix reagent (Applied Biosystems) using an ABI Prism 7500 machine. The 20 $\mu$ reaction volume contained 30ng cDNA, $10 \mu \mathrm{l} 2 \times$ PCR Master mix, and $0.4 \mu \mathrm{l}$ of each primer. After initial denaturation at $95^{\circ} \mathrm{C}$ for $10 \mathrm{~min}, 40 \mathrm{PCR}$ cycles were run at $95^{\circ} \mathrm{C}$ for 15 secs, followed by $60^{\circ} \mathrm{C}$ for $1 \mathrm{~min}$. The primers were: mouse $\beta$-actin: forward: 5'-TGTTACCAACTGGGACGACA-3', reverse: 5'-CTTTTCACGGTTGGCCTTAG-3'; mouse $\alpha$-SMA: forward: $5^{\prime}$ GGCTCTGGGCTCTGTAAGG-3', reverse: 5'-CTCTTGCTCTGGGCTTCATC-3; mouse collagen $\alpha 1$ (I) : forward: 5'-CCAAGGGTAACAGCGGTGAA-3', reverse: 5'CCTCGTTTTCCTTCTTCTCCG-3', mouse TIMP-1: forward: 5'GCATCTCTGGCATCTGGCATC-3', reverse: 5'-GCGGTTCTGGGACTTGTGGGC-3'; mouse MMP-2 : forward: 5'-TTCCCCCGCAAGCCCAAGTG-3', reverse:5'GAGAAAAGCGCAGCGGAGTGACG-3'; and mouse TGF- $\beta 1$ : forward: $5^{\prime}-$ GGTTCATGTCATGGATGGTGC-3', reverse: 5'-TGACGTCACTGGAGTTGTACGG-3'.

\section{Western blotting and marker assays}

Liver extracts were prepared by homogenization of $100 \mathrm{mg}$ tissue in $1 \mathrm{ml}$ immunoprecipitation buffer (see above). Clarified tissue supernatant containing $50 \mu \mathrm{g}$ of total protein was subjected to SDS-PAGE and Western blotting using anti-CCN2 (18), anti$\beta$-actin (see above), or monoclonal anti- $\alpha$-SMA (clone 1A4; Sigma-Aldrich). Intensities of immunoreactive bands were quantified using image analysis software (Scion Corp, Frederick, MD). Serum levels of aspartate aminotransferase (AST) and alanine aminotransferase (ALT) were determined by the Mouse Phenotyping Shared Resource (Ohio State University Comprehensive Cancer Center, Columbus OH). Serum hyaluronic acid (HA) levels were determined using a commercial kit (Corgenix Inc, Broomfield, CO). Acid-soluble hepatic collagen was determined by Sircol ${ }^{\mathrm{TM}}$ assay (Biocolor Ltd., Carrickfergus, UK).

\section{Statistical analysis}

Each experiment was performed between 3 and 8 times. Data were typically obtained from 3-5 animals in each experimental group using duplicate or triplicate determinations for each animal. For comparison of individual data points, students $t$-test was applied and statistical significance set at $\mathrm{p}<0.05$.

\section{Results}

\section{Production of native CCN2 by mouse hepatocytes in vivo}

We first verified that mouse hepatocytes naturally produce $\mathrm{CCN} 2$ in vivo in response to hepatic insult. Ethanol administration caused a robust increase in CCN2 mRNA expression in the liver parenchyma as assessed by in situ hybridization and an increase in the frequency of CCN2-positive hepatocytes from 13\% to $85 \%$ as assessed by FACS (Figure 1B), thus supporting studies of $\mathrm{CCN} 2$ expression in mouse hepatocytes using a transgenic approach.

\section{Cloning and expression of pALB/CCN2 in mouse hepatocytes}

The functionality of pALB/hCCN2 was verified by transient transfection of mouse FL83B hepatocytes in vitro. Using species-specific $\mathrm{CCN} 2$ primers, mock-transfected cells were shown by RT-PCR to contain only the $734 \mathrm{bp} \mathrm{mCCN} 2$ transcript whereas this transcript plus the $632 \mathrm{bp} \mathrm{hCCN} 2$ transcript was present in $\mathrm{pALB} / \mathrm{hCCN} 2$ - transfected cells (Figure 1C, 
panels a,b). As assessed by immunoprecipitation, transfected cells also contained greater quantities of the $38 \mathrm{kDa} \mathrm{CCN} 2$ protein when compared to the mock-transfected cells (Figure $1 \mathrm{C}$, panel d). $\beta$-actin mRNA expression and protein production were comparable in mockand CCN2-transfected cells (Figure 1C, panels c,e). It was thus concluded that the pALB/ hCCN2 plasmid was functional in hepatocytes.

\section{Production and phenotypic characterization of hCCN2 transgenic mice}

Limited PCR performed on tail DNA showed that the intensity of the hCCN2 PCR product was greater in $h c c n 2+/+$ (homozygous) than in $h c c n 2+/$ - (heterozygous) mice, and was absent from wild-type ( $h c c n 2-/-$ ) mice (Figure 2A, upper panel). These data were supported by Southern blotting using a hCCN2 probe (Figure 2A, lower panel) and were subsequently verified by Q-PCR (Figure 2B). The hCCN2 transgene copy number was $2.89 \pm 0.15$ for $h c c n 2+/-(\mathrm{n}=35)$ and $4.77 \pm 0.16$ for $h c c n 2+/+(\mathrm{n}=11)$.

Hepatic hCCN2 mRNA was verified by RT-PCR which further demonstrated that hCCN2 expression was greater in $h c c n 2+/+$ than $h c c n 2+/$ - mice, and that no hCCN2 expression was evident in hccn2-/- littermates (Figure 2C). Hepatic expression of endogenous mCCN2 mRNA was identical between all three strains of mice (Figure 2C). Immunohistochemistry revealed stronger CCN2 staining in the parenchyma of hccn2+/+ livers as compared to hccn2-/- livers (Figure 2C). Additionally increased amounts of immunoreactive CCN2 in hccn2+/+ mice compared to hccn2-/- were demonstrated by Western blot of liver lysates (Figure 2E, inset) and FACS analysis of isolated hepatocytes (Figure 2E).

CCN2 transgenic mice were alert, healthy, active, and exhibited normal growth curves, weights, appetite, fertility, pregnancy rate, gestational period, litter size and birth weight (data not shown). Individual mice in the ZY2 transgenic were maintained up to 29 months of age with no clinical symptoms in either males or females. Neither hccn2+/+ nor hccn2 +/mice exhibited any histological abnormalities. $\mathrm{H}$ and $\mathrm{E}$ staining of liver sections was unremarkable and showed no differences compared to wild-type littermates (Figure 3A). The staining pattern of $\alpha$-SMA or collagen in transgenic mice was also unremarkable and was identical to that of wild-type mice, with $\alpha$-SMA present in the smooth muscle cells of the blood vessels and collagen fibers localized to the vasculature as expected (Figure 3A). Serum liver function tests (AST, ALT) were not significantly altered in transgenic mice (Figure 3B).

\section{Enhanced susceptibility of CCN2 transgenic mice to liver fibrosis}

When animals were chronically treated with a dose of $\mathrm{CCl}_{4}$ that was selected to induce submaximal stimulation of hepatic fibrosis in wild-type mice, the fibrotic response to this dose was noticeably enhanced in transgenic mice (Figures 4,5). This difference was evident when liver sections were stained either for $\alpha$-SMA (Figure 4A) or collagen (Figure 5A) and was more pronounced in homozygous mice than heterozygous mice. As assessed by image analysis, the amount of staining for $\alpha$-SMA or collagen was positively correlated with the $h c c n 2$ genotype and a statistically significant increase was apparent in $h c c n 2+/+$ mice as compared to hecn2-/- mice ( $\mathrm{p}<0.05)$ (Figures 4B, 5B). A statistically significant exacerbated fibrotic response to $\mathrm{CCl}_{4}$ in $h c c n 2+/+$ mice was also evident when hepatic extracts were assessed for $\alpha$-SMA levels by Western blotting (Figure 4C) or for acid-soluble collagen content by Sircol ${ }^{\mathrm{TM}}$ assay (Figure 5C) $(\mathrm{p}<0.05)$. As assessed by Q-RTPCR, treatment of either $h c c n 2-/$ - mice or $h c c n 2+/+$ mice with $\mathrm{CCl}_{4}$ caused an increase in the mRNA expression of $\alpha$-SMA, collagen $\alpha 1$ (1), MMP-2, TIMP-1 (Figure 6A). However, $\mathrm{CCl}_{4}$ induced expression of all transcripts was greater in $h c c n 2+/+$ mice compared and was statistically higher $(\mathrm{p}<0.05)$ for $\alpha$-SMA, collagen $\alpha 1$ (1), and TIMP-1. Expression of TGF$\beta 1$ mRNA in wild type or transgenic mice was moderately enhanced after chronic $\mathrm{CCl}_{4}$ 
treatment but this response was not exacerbated by the presence of the $\mathrm{CCN} 2$ transgene (Figure 6A). Finally, in $\mathrm{CCl}_{4}$-treated animals, circulating $\mathrm{HA}$ levels were significantly greater in $h c c n 2+/+$ mice as compared to $h c c n 2-/$ - mice ( $\mathrm{p}<0.05)$ (Figure 6B).

To verify that the pro-fibrotic effect of the $\mathrm{CCN} 2$ transgene after liver injury was not restricted to the effect of hepatotoxins such as $\mathrm{CCl}_{4}$, mice alternatively underwent $\mathrm{BDL}$ and their livers were examined for collagen deposition two weeks later. As detected by Sirius Red staining, there was a marked increase in BDL-induced collagen deposition in hccn2+/+ mice as compared to hccn2-/- mice ( $\mathrm{p}<0.05$; Figure 7 ) whereas no fibrotic response was present in sham-operated mice (data not shown). These data thus showed that the effects of distinct fibrotic stimuli were exacerbated by expression of the hepatic hCCN2 transgene.

\section{Discussion}

Research over the last 15-20 years has firmly established that CCN2 is involved in fibrosis. While many studies have focused on aspects of CCN2 gene regulation at the molecular level, the precise role of $\mathrm{CCN} 2$ in fibrogenic cascades has been difficult to ascertain because of the lack of availability of high quality purified CCN2 with which to perform critical studies and because its actions as a matricellular protein are difficult, if not impossible, to fully model using in vitro approaches. Moreover, only a limited number of transgenic systems have been reported for CCN2 (24-26) and none of these have addressed either its action in the liver or, somewhat surprisingly, its fibrotic properties. To address these deficiencies, we created transgenic mice that overproduced hepatic CCN2 under the control of the albumin enhancer/promoter in hepatocytes, a legitimate cell type given its ability produce $\mathrm{CCN} 2$ in response to various insults, often downstream of TGF- $\beta$ (Figure 1; $(10-15))$

Our major finding was that hepatocyte overexpression of CCN2 per se was non-fibrotic but that it resulted in a potentiation of $\mathrm{CCl}_{4}$ - or BDL-stimulated hepatic fibrosis. It is important to note that, under normal circumstances, there was no histopathology or evidence of HSC activation in the livers of $\mathrm{CCN} 2$ transgenic mice. In vitro studies have previously shown that $\mathrm{CCN} 2$ does not interact with quiescent HSC but that it potentiates fibrogenic and survival pathways in activated HSC which express up-regulated levels of CCN2 receptors such as integrin $\alpha v \beta 3$ (27). This fact, coupled with the absence of other injury cascades in transgenic livers that might otherwise cause HSC activation, likely explains the inability of the CCN2 transgene alone to drive fibrosis.

Fibrosing stimuli ordinarily cause the elaboration of multiple signaling pathways as opposed to changes in CCN2 expression alone. Thus, the pathophysiological role of CCN2 is best evaluated in the context of the fibrogenic cascades of which it is a normal component. We therefore conducted additional studies in transgenic mice subjected to $\mathrm{CCl}_{4}$ treatment or $\mathrm{BDL}$ and found that the presence of the hepatocyte $\mathrm{CCN} 2$ transgene constitutes a 'first hit' that sensitized the liver to a different 'second hit', resulting in more advanced fibrosis.

The increase in fibrosis-susceptibility in $\mathrm{CCN} 2$ transgenic mice may be related to the additive effects of the hCCN2 protein on intrinsic $\mathrm{CCN} 2$ target pathways that were activated by $\mathrm{CCl}_{4}$ or $\mathrm{BDL}$, or their co-operative binding interactions with other molecules in the fibrogenic cascade such as fibronectin or TGF- $\beta 1$. For example, $\mathrm{CCN} 2$ binds to fibronectin (28) and increases integrin-dependent adhesion to fibronectin by fibroblasts (29), chondrocytes (30), hepatic oval cells (31) or activated mouse HSC (D.R.Brigstock and G. Huang, unpublished observations). Also, TGF- $\beta 1$ binds directly to CCN2, which increases TGF- $\beta$ bioactivity due to its enhanced affinity for the Type II TGF- $\beta$ receptor (32), a phenomenon that may account for the reported synergism between CCN2 and TGF- $\beta$ in 
stimulating dermal fibrosis in vivo (33). A synergistic action of this type seems plausible in our model since many fibrotic readouts downstream of TGF- $\beta$ were amplified in $\mathrm{CCl}_{4}$ treated transgenic mice versus wild type mice, even though expression of $\mathrm{CCl}_{4}$-induced TGF- $\beta$ itself was comparable between the two groups of animals. While there are no other transgenic CCN2 fibrosis models with which to draw comparisons, expression of a CCN2 transgene in mouse podocytes in vivo was insufficient to cause glomerular damage, but when challenged in a setting of a streptozotocin-induced type 1 diabetes the transgenic mice exhibited increased glomerular pathology as compared to wild-type mice (25). This exacerbated response included enhanced matrix expansion which was proposed to reflect the combined matrigenic actions of CCN2 and other factors such as TGF- $\beta$ (25). Lastly, cooperative interactions between CCN2 and TGF- $\beta$ in vivo were shown in Balb/c mice which, though genetically resistant to Smad-3-mediated bleomycin-induced lung fibrosis, became susceptible to fibrosis when treated concomitantly with bleomycin and a CCN2-expressing adenovirus (34). With respect to genetic-resistance, the FVB strain used in our study is relatively resistant to hepatic fibrosis (35) raising the question of whether this phenomenon might account for the lack of hepatic phenotype in the FVB hCCN2 transgenic mice. However, we have back-crossed the hCCN2 transgene on to the more susceptible Balb/c strain (35) and have found that liver histology remains normal over all generations examined (up to and including F11; data not shown). Thus the various in vivo studies to date show that CCN2 overexpression alone does not cause tissue damage and/or fibrosis and that additional changes in the micro-environment are required for the deleterious functions of CCN2 to be manifested, a mode of action that is entirely consistent with its function as a matricellular protein.

In conclusion, our studies demonstrate that expression of an albumin promoter-driven CCN2 transgene in mouse hepatocytes in vivo does not cause hepatic injury or fibrosis but renders the livers more susceptible to the injurious actions of another fibrotic stimulus. These studies provide further evidence in support for a central role of CCN2 in hepatic fibrosis and emphasize the role of the micro-environment in regulating the pro-fibrotic action of $\mathrm{CCN} 2$.

\section{Acknowledgments}

We thank Dr Dr Richard Palmiter (University of Washington, Seattle, WA) for providing p2335A-1. We acknowledge the help of Dr Donna Kusewitt with liver function tests and Dr Andrei Radulescu with animal surgery. This work is dedicated to the memory of Dr Donald R Cooney (1943 - 2008) who was a champion of surgical research and established the Pediatric Surgery Research Laboratory at Nationwide Children's Hospital in 1991.

Financial Support: This work was supported by NIH grants AA 012817 and AA 016003 awarded to DRB

\section{Abbreviations}

$\begin{array}{ll}\text { ALT } & \text { alanine aminotransferase } \\ \text { AST } & \text { aspartate aminotransferase } \\ \text { a-SMA } & \text { alpha-smooth muscle actin } \\ \text { BDL } & \text { bile duct ligation } \\ \text { CCN2 } & \text { connective tissue growth factor } \\ \text { CCl }_{4} & \text { carbon tetrachloride } \\ \text { FACS } & \text { fluorescence-activated cell sorting } \\ \text { HSC } & \text { hepatic stellate cells }\end{array}$




$\begin{array}{ll}\text { hCCN2 } & \text { human CCN2 } \\ \text { MCCN2 } & \text { mouse CCN2 } \\ \text { Q-RTPCR } & \text { quantitative real time PCR } \\ \text { PCR } & \text { polymerase chain reaction } \\ \text { RT-PCR } & \text { reverse-transcriptase PCR } \\ \text { TGF- } \beta & \text { transforming growth factor beta }\end{array}$

\section{References}

1. Brigstock DR. The connective tissue growth factor/cysteine-rich 61/nephroblastoma overexpressed (CCN) family. Endocr Rev. 1999; 20:189-206. [PubMed: 10204117]

2. Chen CC, Lau LF. Functions and mechanisms of action of CCN matricellular proteins. Int J Biochem Cell Biol. 2009; 41:771-783. [PubMed: 18775791]

3. Rachfal AW, Brigstock DR. Connective tissue growth factor (CTGF/CCN2) in hepatic fibrosis. Hepatol Res. 2003; 26:1-9. [PubMed: 12787797]

4. Williams EJ, Gaca MD, Brigstock DR, Arthur MJ, Benyon RC. Increased expression of connective tissue growth factor in fibrotic human liver and in activated hepatic stellate cells. J Hepatol. 2000; 32:754-761. [PubMed: 10845662]

5. Sedlaczek N, Jia JD, Bauer M, Herbst H, Ruehl M, Hahn EG, Schuppan D. Proliferating bile duct epithelial cells are a major source of connective tissue growth factor in rat biliary fibrosis. Am J Pathol. 2001; 158:1239-1244. [PubMed: 11290541]

6. George J, Tsutsumi M. siRNA-mediated knockdown of connective tissue growth factor prevents Nnitrosodimethylamine-induced hepatic fibrosis in rats. Gene Ther. 2007; 14:790-803. [PubMed: 17344905]

7. Tamatani T, Kobayashi H, Tezuka K, Sakamoto S, Suzuki K, Nakanishi T, Takigawa M, et al. Establishment of the enzyme-linked immunosorbent assay for connective tissue growth factor (CTGF) and its detection in the sera of biliary atresia. Biochem Biophys Res Commun. 1998; 251:748-752. [PubMed: 9790981]

8. Gressner AM, Yagmur E, Lahme B, Gressner O, Stanzel S. Connective tissue growth factor in serum as a new candidate test for assessment of hepatic fibrosis. Clin Chem. 2006; 52:1815-1817. [PubMed: 16858074]

9. Gressner OA, Gressner AM. Connective tissue growth factor: a fibrogenic master switch in fibrotic liver diseases. Liver Int. 2008; 28:1065-1079. [PubMed: 18783549]

10. Ujike K, Shinji T, Hirasaki S, Shiraha H, Nakamura M, Tsuji T, Koide N. Kinetics of expression of connective tissue growth factor gene during liver regeneration after partial hepatectomy and Dgalactosamine- induced liver injury in rats. Biochem Biophys Res Commun. 2000; 277:448-454. [PubMed: 11032743]

11. Hirasaki S, Koide N, Ujike K, Shinji T, Tsuji T. Expression of Nov, CYR61 and CTGF genes in human hepatocellular carcinoma. Hepatol Res. 2001; 19:294-305. [PubMed: 11251312]

12. Konishi M, Kato S, Kajihara M, Yamagishi Y, Horie Y, Aiso S, Ishii H. Expression of connective tissue growth factor (CTGF) in alcoholic liver fibrosis and in HEPG2 cell line stably expressiong cytochrome P-4502E1. Hepatology. 2002; 36:248A.

13. Shin JY, Hur W, Wang JS, Jang JW, Kim CW, Bae SH, Jang SK, et al. HCV core protein promotes liver fibrogenesis via up-regulation of CTGF with TGF-beta1. Exp Mol Med. 2005; 37:138-145. [PubMed: 15886528]

14. Gressner OA, Lahme B, Rehbein K, Siluschek M, Weiskirchen R, Gressner AM. Pharmacological application of caffeine inhibits TGF-beta-stimulated connective tissue growth factor expression in hepatocytes via PPARgamma and SMAD2/3-dependent pathways. J Hepatol. 2008; 49:758-767. [PubMed: 18486259] 
15. Weng HL, Ciuclan L, Liu Y, Hamzavi J, Godoy P, Gaitantzi H, Kanzler S, et al. Profibrogenic transforming growth factor-beta/activin receptor-like kinase 5 signaling via connective tissue growth factor expression in hepatocytes. Hepatology. 2007; 46:1257-1270. [PubMed: 17657819]

16. Martinerie C, Viegas-Pequignot E, Guenard I, Dutrillaux B, Nguyen VC, Bernheim A, Perbal B. Physical mapping of human loci homologous to the chicken nov proto- oncogene. Oncogene. 1992; 7:2529-2534. [PubMed: 1334251]

17. Pinkert CA, Ornitz DM, Brinster RL, Palmiter RD. An albumin enhancer located $10 \mathrm{~kb}$ upstream functions along with its promoter to direct efficient, liver-specific expression in transgenic mice. Genes Dev. 1987; 1:268-276. [PubMed: 3678824]

18. Ball DK, Moussad EE, Rageh MA, Kemper SA, Brigstock DR. Establishment of a recombinant expression system for connective tissue growth factor (CTGF) that models CTGF processing in utero. Reproduction. 2003; 125:271-284. [PubMed: 12578541]

19. Klaunig JE, Goldblatt PJ, Hinton DE, Lipsky MM, Chacko J, Trump BF. Mouse liver cell culture. I. Hepatocyte isolation. In Vitro. 1981; 17:913-925. [PubMed: 6273298]

20. Leask A, Chen S, Pala D, Brigstock DR. Regulation of CCN2 mRNA expression and promoter activity in activated hepatic stellate cells. J Cell Commun Signal. 2008; 2:49-56. [PubMed: 18798011]

21. Chang ML, Yeh CT, Chang PY, Chen JC. Comparison of murine cirrhosis models induced by hepatotoxin administration and common bile duct ligation. World J Gastroenterol. 2005; 11:41674172. [PubMed: 16015684]

22. Surveyor GA, Brigstock DR. Immunohistochemical localization of connective tissue growth factor (CTGF) in the mouse embryo between days 7.5 and 14.5 of gestation. Growth Factors. 1999; 17:115-124. [PubMed: 10595311]

23. Rageh MA, Moussad EE, Wilson AK, Brigstock DR. Steroidal regulation of connective tissue growth factor (CCN2; CTGF) synthesis in the mouse uterus. Mol Pathol. 2001; 54:338-346. [PubMed: 11577177]

24. Nakanishi T, Yamaai T, Asano M, Nawachi K, Suzuki M, Sugimoto T, Takigawa M. Overexpression of connective tissue growth factor/hypertrophic chondrocyte-specific gene product 24 decreases bone density in adult mice and induces dwarfism. Biochem Biophys Res Commun. 2001; 281:678-681. [PubMed: 11237711]

25. Yokoi H, Mukoyama M, Mori K, Kasahara M, Suganami T, Sawai K, Yoshioka T, et al. Overexpression of connective tissue growth factor in podocytes worsens diabetic nephropathy in mice. Kidney Int. 2008; 73:446-455. [PubMed: 18075496]

26. Smerdel-Ramoya A, Zanotti S, Stadmeyer L, Durant D, Canalis E. Skeletal overexpression of connective tissue growth factor impairs bone formation and causes osteopenia. Endocrinology. 2008; 149:4374-4381. [PubMed: 18535099]

27. Gao R, Brigstock DR. Connective tissue growth factor (CCN2) induces adhesion of rat activated hepatic stellate cells by binding of its C-terminal domain to integrin alphavbeta3 and heparan sulfate proteoglycan. J Biol Chem. 2004; 279:8848-8855. [PubMed: 14684735]

28. Yoshida K, Munakata H. Connective tissue growth factor binds to fibronectin through the type I repeat modules and enhances the affinity of fibronectin to fibrin. Biochim Biophys Acta. 2007; 1770:672-680. [PubMed: 17239539]

29. Chen Y, Abraham DJ, Shi-Wen X, Pearson JD, Black CM, Lyons KM, Leask A. CCN2 (connective tissue growth factor) promotes fibroblast adhesion to fibronectin. Mol Biol Cell. 2004; 15:5635-5646. [PubMed: 15371538]

30. Hoshijima M, Hattori T, Inoue M, Araki D, Hanagata H, Miyauchi A, Takigawa M. CT domain of CCN2/CTGF directly interacts with fibronectin and enhances cell adhesion of chondrocytes through integrin alpha5beta1. FEBS Lett. 2006

31. Pi L, Ding X, Jorgensen M, Pan JJ, Oh SH, Pintilie D, Brown A, et al. Connective tissue growth factor with a novel fibronectin binding site promotes cell adhesion and migration during rat oval cell activation. Hepatology. 2008; 47:996-1004. [PubMed: 18167060]

32. Abreu JG, Ketpura NI, Reversade B, De Robertis EM. Connective-tissue growth factor (CTGF) modulates cell signalling by BMP and TGF-beta. Nat Cell Biol. 2002; 4:599-604. [PubMed: 12134160] 
33. Mori T, Kawara S, Shinozaki M, Hayashi N, Kakinuma T, Igarashi A, Takigawa M, et al. Role and interaction of connective tissue growth factor with transforming growth factor-beta in persistent fibrosis: A mouse fibrosis model. J Cell Physiol. 1999; 181:153-159. [PubMed: 10457363]

34. Bonniaud P, Martin G, Margetts PJ, Ask K, Robertson J, Gauldie J, Kolb M. Connective tissue growth factor is crucial to inducing a profibrotic environment in "fibrosis-resistant" BALB/c mouse lungs. Am J Respir Cell Mol Biol. 2004; 31:510-516. [PubMed: 15256388]

35. Hillebrandt S, Goos C, Matern S, Lammert F. Genome-wide analysis of hepatic fibrosis in inbred mice identifies the susceptibility locus Hfib1 on chromosome 15. Gastroenterology. 2002; 123:2041-2051. [PubMed: 12454860] 
A

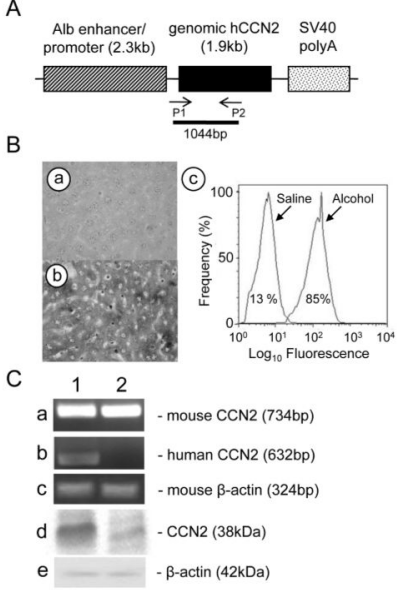

Figure 1. Cloning and testing of human CCN2 transgene construct and production of native CCN2 by hepatocytes in vivo

(A) A $1.9 \mathrm{~kb}$ fragment containing the human CCN2 gene was placed downstream of the albumin-enhancer to produce $\mathrm{pALB} / \mathrm{hCCN} 2$ as described in Materials and Methods. Primers P1 and P2 were used for genotyping. (B) Wild-type FVB/n mice were administered (a) 6g/ $\mathrm{kg}$ ethanol or (b) saline by i.p. injections at 0,8 and 16 hours. Mice were sacrificed 8 hours later and either $(\mathrm{a}, \mathrm{b}$,$) fixed tissue was processed for in situ hybridization to detect CCN2$ mRNA or (c) hepatocytes were isolated from fresh tissue and tested for the presence of CCN2 protein by FACS analysis using a CCN2 polyclonal antibody. (C) FL83B hepatocytes were either mock transfected (lane 1) or transiently transfected with pALB/hCCN2 (lane 2) for 48 hours, after which RNA or protein were subsequently extracted from parallel cultures of cells. The figure shows the results of reverse-transcriptase PCR using primers designed to detect (a) mCCN2 mRNA, (b) hCCN2 mRNA or (c) mouse $\beta$-actin. Immunoprecipitation using anti-CCN2 (d) showed that higher levels of CCN2 protein were present in lysates from hCCN2-transfected cells as compared to the mock-transfected counterparts, while levels of $\beta$-actin determined by Western blot (e) were comparable. 


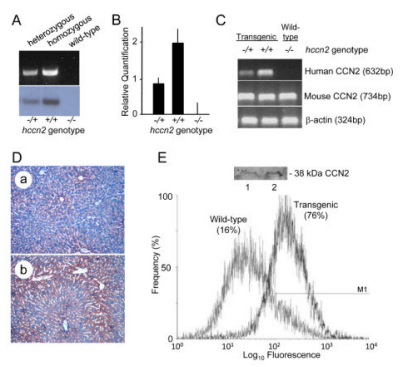

Figure 2. Genotypic characterization and CCN2 production in livers of hCCN2 transgenic mice (A) Semi-quantitative PCR (upper panel) and Southern blot (lower panel) of DNA isolated from mouse tails. (B) Q-PCR in which each DNA sample was analyzed in 3 separate reactions (mean +/-s.d). Representative data are shown for three individual mice, each of which has a distinct hecn 2 genotype. (C) RT-PCR of hepatic RNA from wild-type or transgenic mice using mCCN2-specific or hCCN2-specific primers confirming the presence of hCCN2 transcripts in transgenic but not wild-type mice. (D) CCN2 immunohistochemistry of liver sections from (a) wild-type (hccn2-/-) or (b) transgenic (hccn2+/+) mice. (E) FACS analysis of CCN2-positive hepatocytes isolated from the livers of wild-type or transgenic (hccn2 +/+) mice. The inset shows a CCN2 Western blot of whole liver lysate normalized for total protein loading from wild type (lane 1) or transgenic (hccn2+/+) (lane 2) mice. 


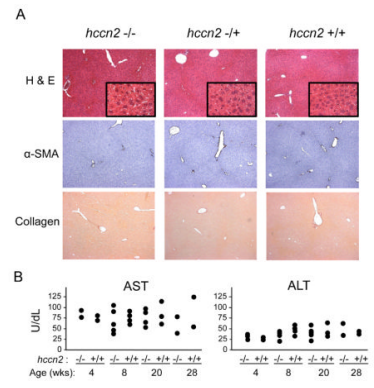

Figure 3. CCN2 transgenic mice exhibit normal hepatic histology and LFTs

(A) Histological features of livers from wild-type or transgenic mice. Liver sections of mice were stained with H\&E (top row), anti- $\alpha$-SMA (middle row), or Sirius Red (bottom row) (20x; insets show detail at 40x). Data are representative of 24 mice observed from 8 individual experiments ( $\mathrm{n}=3$ per group) (B) Serum ALT and AST levels in individual wildtype or transgenic mice over the first 28 weeks of life. 
A

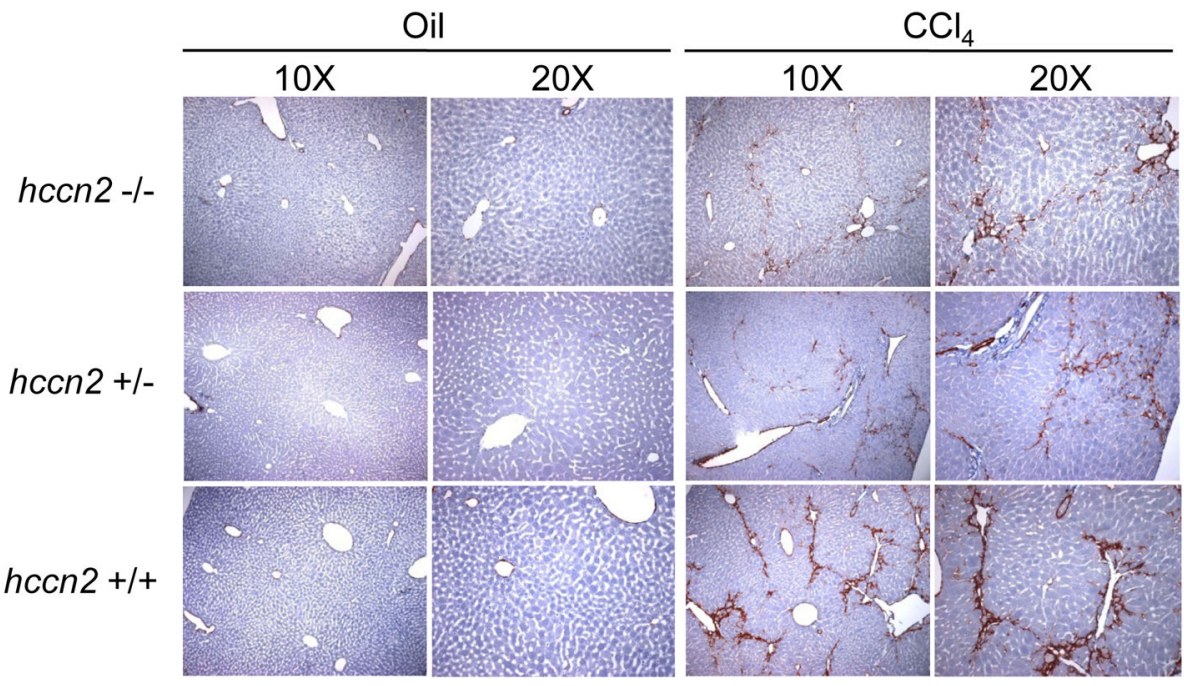

B

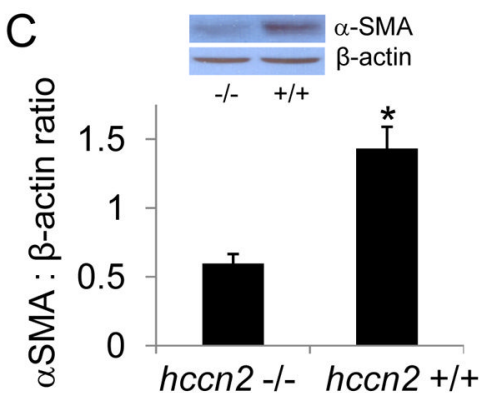

Figure 4. Enhanced $\mathrm{CCl}_{4}$-induced $\alpha$-SMA production $\mathrm{CCN} 2$ transgenic mice as compared to wild type mice

(A) Mice were treated i.m. once per day on 4 successive days each week for 5 weeks with either $30 \mu \mathrm{l}$ of vegetable oil or a mixture of $0.5 \mu \mathrm{CCl}_{4}$ in $29.5 \mu \mathrm{l}$ of vegetable oil. Livers were resected, fixed, and processed for $\alpha$-SMA immunohistochemistry. Staining is representative of 24 mice observed from 8 individual experiments ( $n=3$ per group). (B) $\alpha$ SMA staining on tissue sections was quantified by image analysis of ten $20 \times$ fields (mean \pm s.d). *p<0.05 versus "hccn2 -/-". (C) Presence of $\alpha$-SMA in hepatic tissue extracts relative to that of $\beta$-actin as assessed by densitometric scanning of Western blots from 4 animals per group (mean \pm s.d). *p<0.05 versus "hccn2 -/-". The inset shows a representative Western blot. 
A
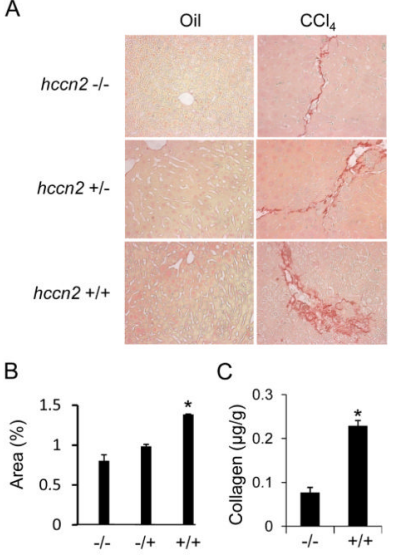

Figure 5. Enhanced $\mathrm{CCl}_{4}$-induced collagen deposition $\mathrm{CCN} 2$ transgenic mice as compared to wild type mice

(A) Mice were treated as described in Figure 4 and liver sections were stained with Sirius Red to detect collagen. Staining is shown at $20 \times$ and is representative of 24 mice observed from 8 individual experiments ( $n=3$ per group). (B) Sirius Red staining on tissue sections was quantified by image analysis of ten $20 \times$ fields (mean \pm s.d). *p<0.05 versus "hccn2 -/-". (C) Sircol TM assay of acid-soluble collagen in hepatic tissue extracts (mean \pm s.d.; $n=5$ per group). *p<0.05 versus "hccn $2-/-"$. 


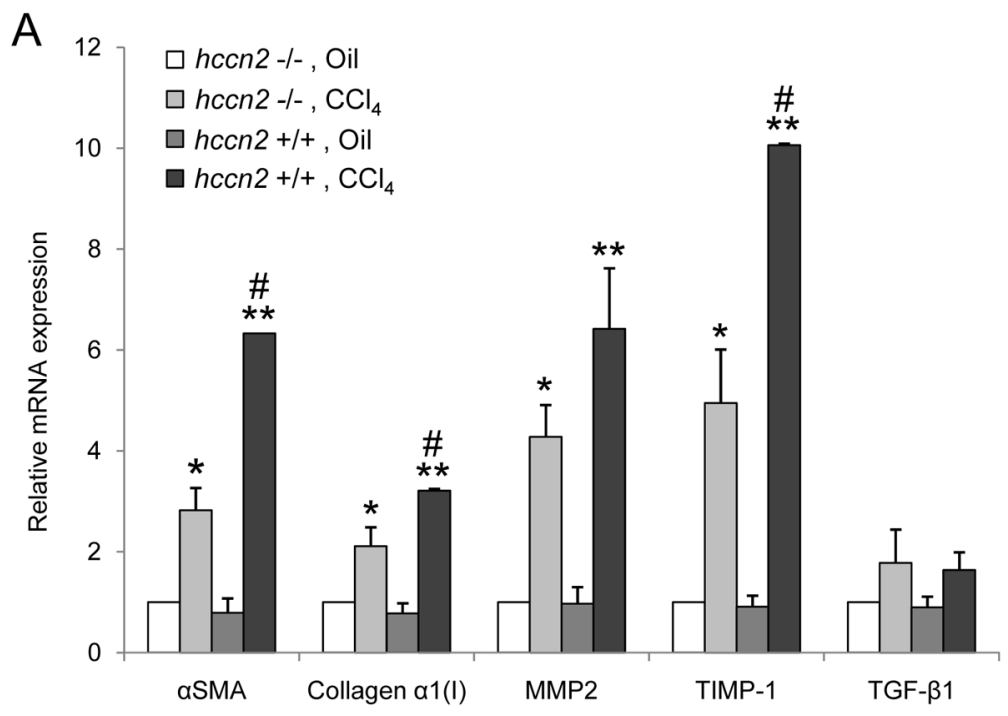

B

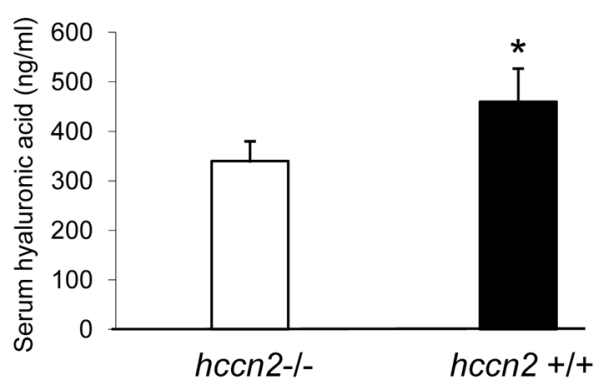

Figure 6. Enhanced $\mathrm{CCl}_{4}$-induced production of fibrosis-related gene products in $\mathrm{CCN} 2$ transgenic mice as compared to wild type mice

(A). Q-RTPCR of mRNA from hccn2 -/- or hccn2 +/+ livers after chronic exposure to $\mathrm{CCl}_{4}$ for 5 weeks. Data are triplicate determinations (mean \pm s.d.) of relative mRNA expression from 3 mice in each group and are representative of three experiments. * $\mathrm{p}<0.05 \mathrm{v}$ " $h c c n 2-/-$, Oil"; ** p<0.05 v "hccn2+/+, Oil"; \# p < 0.05 v "hccn2-/-, $\mathrm{CCl}_{4}$ ". (B) Serum HA levels in hccn2-/- or hccn2+/+ mice after chronic $\mathrm{CCl}_{4}$ treatment for 5 weeks (mean \pm s.d.; $\mathrm{n}=5$ per group). *p<0.05 v “hccn2-/-". 
A

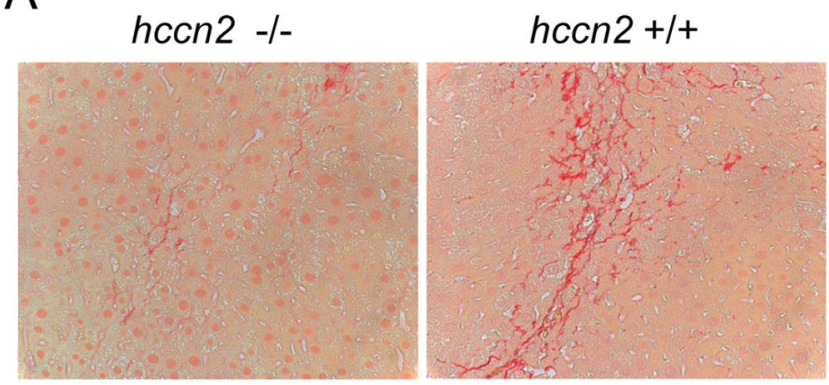

B

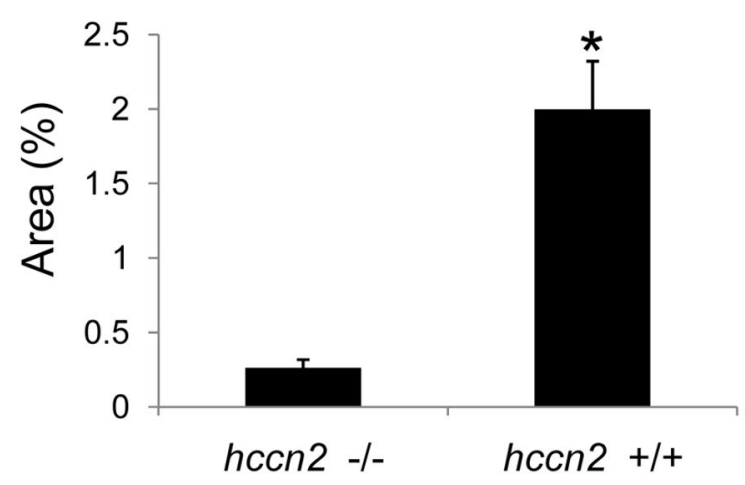

Figure 7. Enhanced BDL-induced collagen deposition CCN2 transgenic mice as compared to wild type mice

(A) Mice were subjected to BDL and, two weeks later, livers were removed, sectioned and stained with Sirius Red (20x). (B) Quantification of Sirius Red staining of tissue sections by image analysis of ten $20 \times$ fields from 4 mice in each group (mean \pm s.d). ${ }^{*} \mathrm{p}<0.05$ versus "hccn2 -/-" 